\title{
INFLUÊNCIA DA COBERTURA MORTA NO COMPORTAMENTO DOS HERBICIDAS IMAZAQUIN E CLOMAZONE ${ }^{1}$
}

\author{
BENEDITO N. RODRIGUES ${ }^{2}$
}

\begin{abstract}
RESUMO
Experimentos de campo e bioensaios em casa-devegetação foram realizados para se estudar a influência da cobertura morta de trigo (Triticum aestivum L.) no comportamento dos herbicidas imazaquin \{ácido 2-[4,5 dihidro-4metil-4-(1-metiletil)-5-oxo- 1H-imidazol-2-ilo] -3-quinolinacarboxílico\} e clomazone \{2-[(2-clorofenil)metil]-4,4dimetil-3-isoxazolídinona\}, aplicados em pré-emergência na

cultura da soja [Glycine $\max ($ L.) Merril], no sis tema de plantio direto. $\mathrm{O}$ clomazone mostrou evidências de ter sido interceptado pela cobertura morta. A presença da cobertura morta não influiu na retenção do imazaquin, sendo este lixiviado da palha para o solo com as chuvas que ocorreram após a aplicação.

Palavras-chave: plantio direto, soja, Glycine max.
\end{abstract}

\section{ABSTRACT \\ The influence of straw mulch on the behaviour of the residual herbicides imazaquin and clomazone}

Field experiments and glasshouse bioassays were conducted to determine the influence of winter wheat (Triticum aestivum L.) straw mulch on the behaviour of the herbicides imazaquin \{2-[4,5-dihydro-4-methyl-4-(1-methylethyl)-5oxo-1H-imidazol-2-yl]-3-quinolinecarboxylic acid) and clomazone $\quad\{2-[(2-$ chlorophenyl $)$ methyl $]-4,4-$ dimethyl-3-

\section{INTRODUÇÃO}

A cobertura morta, constituída por resíduos vegetais, desempenha importante papel no sucesso dos diversos sistemas agrícolas: serve como camada isolante, protegendo o solo das amplitudes térmicas diurnas, reduzindo a evaporação, mantendo o solo úmido mesmo durante longo período de estiagem, enriquecendo-o em matéria orgânica e proporcionando ambiente favorável ao desenvolvimento das populações de invertebrados. Além dessas vantagens, a cobertura moita pode funcionar ainda como um valioso elemento no

1 Recebido para publicação em 31/03/93 e na forma revisada em 21/09/93. $2 \mathrm{Eng}^{\circ} \mathrm{Agr}^{\circ}, \mathrm{PhD}$, Pesquisador do Instituto Agronômico do Paraná,

TAPAR, Caixa Postal 1331, CEP 86010-970, Londrina, PR. isoxazolidinone \}, wich had been applied to pre-emergence soybean (Glycine max) in a no-till system. There was evidence that clomazone had been intercepted by the straw whilst imazaquin was leached ínto the soil by rain.

Additional index words: no-till, soybean, Glycine $\max$.

controle das plantas daninhas, pois um terreno com cobertura uniforme e espessa de resíduos, apresenta infestação bastante inferior àquela que se desenvolveria se o mesmo fosse descoberto (Almeida, 1981).

As coberturas mortas, no entanto, diferem muito entre si quanto ao tempo que levam para se decompor e, também, quanto à capacidade de liberarem substâncias alelopáticas capazes de inibir a germinação das sementes de algumas espécies de plantas daninhas presentes no solo. Almeida (1988), utilizando diversas coberturas mortas, verificou que os resíduos da aveia são, depois do nabo-forrageiro, os que se decompõem mais rapidamente. Porém, dada a maior massa inicial produzida mantém, por mais tempo, maior quantidade de cobertura morta sobre o terreno. Daí, a sua superior capacidade de controlar as infestantes. Diante disso, esse mesmo autor cita também que, se algumas culturas de

Planta Daninha, v. 11, n. 1/2, 1993. 
verão como soja, feíjão e milho forem semeadas no sistema de plantio direto sobre coberturas mortas densas, de lenta decomposição e com ação alelopática; poderia haver a possibilidade de se reduzir ou até mesmo dispensar o uso de herbicidas.

Sabe-se, porém, que os mesmos herbicidas pré-emergentes recomendados no plantio convencional, em solo bem preparado, livre de torrões e restos vegetais, são utilizados também numa situação onde há grande quantidade de restos de culturas, ou seja, de coberturas mortas (Almeida \& Rodrigues, 1988). Nessas condições, numa segunda hipótese, nem sempre a concentração inicialmente aplicada atingiria o solo, podendo ficar retida boa parte desses produtos na palha que cobre o terreno. Por esse motivo, alguns agricultores costumam aumentar as doses dos herbicidas pré-emergentes em plantio direto, exatamente para compensar possíveis perdas desses produtos, os quais ficariam adsorvidos à palha, não conseguindo atingir o solo.

Esse fato tem chamado a atenção de diversos pesquisadores. Estudos realizados por Pastana (1972) nos EUA mostraram que quando atrazine foi aplicado em solo com cobertura morta de aveia, o peso da matéria seca das plantas daninhas que ali se desenvolveram foi maior que em solo sem cobertura morta, sugerindo que parte do produto ficou retida na palha. A redução do peso da matéria seca das infestantes, em solo com cobertura, foi conseguida com o aumento da dose do produto. Bauman (1977) verificou que, em aplicações de atrazine sobre restos de centeio, 30\% a menos do produto atingiu o terreno do que quando pulverizado diretamente em terra nua.

A origem e a quantidade da cobertura morta podem influir na capacidade de um herbicida residual em atingir o solo no sistema de plantio direto. Lowder \& Weber (1979) citam que a retenção do atrazine pelos restos vegetais de milho e aveia pode explicar, em parte, a necessidade de se utilizar doses mais altas do herbicida sobre essas coberturas mortas do que em plantio convencional; citam também que mais atrazine foi removida por chuva dos restos vegetais de aveia do que de milho. Banks \& Robinson (1982) verificaram que, com o aumento da quantidade de cobertura morta de trigo, há uma correspondente redução na quantidade de metribuzin que consegue atingir o solo no sistema de plantio direto de soja.

Outros fatores citados por alguns autores, que exercem grande influência na retenção dos herbicidas pela palha, são a quantidade e a época das chuvas que ocorrem após a aplicação. Banks \& Robinson (1986) obtiveram um aumento na quantidade de metolachlor, alachlor e acetochlor na superfície do solo, sob a cobertura morta de trigo, coin o aumento na quantidade de água de irrigação. Lowder \& Weber (1979) verificaram que, quando $100 \mathrm{~mm}$ de água são aplicados imediatamente após a aplicação do atrazine, $87 \%$ do herbicida é removido da cobertura morta, mas, se forem aplicados ao $7^{\circ}$ dia, são removidos $77 \%$ do produto.

Alguns autores, no entanto, citam que a solubilidade em água é a principal característica que confere maior ou menor capacidade de um herbicida em atingir o solo no sistema de plantio díreto. Comparando os herbicidas metolachlor e alachlor, Strek \& Weber (1982) verificaram que o primeiro foi menos interceptado pela cobertura morta de trigo, possivelmente por ser mais solúvel que o segundo; sendo solúveis em água, quando da primeira chuva após a aplicação, são lavados da palha para o solo (Almeida, 1992).

Outra característica que pode exercer essa influência é a volatilidade. O clomazone, por exemplo, sendo relativamente volátil (Almeida \& Rodrigues, 1988), poderia ter sua

volatilidade ainda mais acentuada quando aplicado sobre cobertura morta do que em solo nu (Thelan et al., 1986), reduzindo em mais de $40 \%$ a quantidade do produto que atinge o solo no sistema de plantio direto (Mills et al., 1989).

Dentro dessa linha de pesquisa, delineou-se o presente trabalho, cujo objetivo foi estudar o comportamento dos herbicidas imazaquin e clomazone quando aplicados sobre cobertura morta de trigo, no sistema de plantio direto.

\section{MATERIAL E MÉTODOS}

O primeiro experimento foi realizado com o herbicida imazaquin (Scepter, $150 \mathrm{~g} / 1$ ), cuja solubilidade em água a $25^{\circ} \mathrm{C}$ é de $60 \mathrm{ppm}$ e a pressão de vapor a $45^{\circ} \mathrm{C}$ é de $2.10^{-8}$ mm Hg (Almeida \& Rodrigues, 1988). O experimento foi instalado no Centro Experimental do IAPAR em Londrina, PR, local que possui as seguintes caracteristicas: clima Cfa da escala de Koeppen, solo tipo Latossolo-Roxo distrófico, com horizonte A moderado, de textura argilosa ( $81 \%$ de argila, $8 \%$ de silte e $11 \%$ de areia), fase floresta tropical perenifólia e relevo suave ondulado $\left(\operatorname{LRd}_{1}\right)$. A análise desse solo revelou os seguintes dados: $\mathrm{C}=1,77 \%$; $\mathrm{P}=9,3 \mathrm{ppm} ; \mathrm{Al}^{+3}=0,12 ; \mathrm{Ca}^{+2}=3,25 ; \mathrm{Mg}^{+2}=1,77 ; \mathrm{K}^{+}=$ 0,40 (m.e. $/ 100 \mathrm{~g}$ de solo) e $\mathrm{pH}=4,9$. A cultura de inverno utilizada foi o trigo, colhido com colheitadeira automotriz, equipada com picador de palha, semeando-se a soja, como cultura de verão, no sistema de plantio direto.

$\mathrm{O}$ delineamento experimental adotado foi o de blocos ao acaso, coin parcelas subdivididas, com quatro repetições. Os tratamentos foram constituídos pelas seguintes quantidades de cobertura morta: 0 , com hastes, 750, 1500, 3000 e $6000 \mathrm{~kg} /$ ha de matéria seca. Os subtratamentos foram constituídos pelas doses do herbicida imazaquin, aplicado a 0 , $0,075,0,1125$ e $0,15 \mathrm{~kg} / \mathrm{ha}$, correspondendo respectivamente às doses zero, $50 \% \mathrm{~N}, 75 \% \mathrm{~N}$ e $100 \% \mathrm{~N}$ (onde $\mathrm{N}=$ dose normal). Na quantidade "zero" de palha, esta foi rastelada e as hastes remanescentes de trigo foram cortadas e retiradas da parcela, deixando o solo totalmente descoberto. No tratamento "com bastes", a palha foi rastelada e retirada da parcela, mas as hastes de trigo não foram cortadas. Nos demais tratamentos todas as parcelas foram rasteladas, a palha foi pesada e redistribuída manualmente.

As subparcelas tiveram as dimensões de $3 \times 6=18 \mathrm{~m} 2$. Lateralmente a cada subparcela foram deixadas duas entrelinhas de soja não tratadas, que foram utilizadas como termo de comparação nas avaliações visuais. Cada subparcela foi constituída por seis linhas espaçadas de $0,5 \mathrm{~m}$. Nas cabeceiras das parcelas foram deixados arruamentos de $1,0 \mathrm{~m}$ de largura para trânsito dentro do ensaio. A área útil de cada subparcela foi de $2 \times 5=10 \mathrm{~m}^{2}$. A cabeceira da subparcela ( 3 $\mathrm{x} 1=3 \mathrm{~m}^{2}$ ) foi utilizada apenas para amostragem de solo para bioensaio. 
A cultivar de soja utilizada foi a "Paranagoiana", semeada mecanicamente com semeadeira de plantio direto "Jumil 2200 PD" de 5 linhas, densidade de 20 sementes/ metro linear, espaçamento de $0,5 \mathrm{~m}$, profundidade de $0,05 \mathrm{~m}$, aplicando-se no sulco de semeadura $300 \mathrm{~kg} / \mathrm{ha}$ de adubo fórmula 00-30-10. 0 herbicida imazaquin foi aplicado em pré-emergência, imediatamente após a semeadura da soja, coin pulverizador de pressão constante (CO2), munido com barra de 6 bicos Teejet Flat Spray 80.02, distanciados 0,5 m entre si ( $3 \mathrm{~m}$ de alcance), vazão de $200 \mathrm{I} / \mathrm{ha}$. As condições climáticas quando da aplicação do produto encontram-se na Tabela 1.

Foram realizadas avaliações visuais de cobertura do solo pelas plantas daninhas no subtratamento sem herbicida, e de fitotoxicidade à cultura e controle de plantas daninhas nos demais subtratamentos. Considerou-se o valor 30 como o máximo de fitotoxicidade na cultura e o valor 70 como o mínimo de controle de plantas daninhas aceitável na prática. As principais espécies infestantes deste experimento foram capim-marmelada (Brachiaria plantaginea (Link) Hitch) e trigo (Triticum aestivum L.) este, na forma de tiguera, ocorrendo ainda, mais tarde, o picão-preto (Bidens pilosa $\mathrm{L}$.)

$\mathrm{O}$ experimento foi levado à produção, tendo-se também calculado o peso da biomassa fresca das plantas daninhas. Os dados foram submetidos à análise de variância, utilizando-se o teste de Tukey ao nível de 5\% de probabilidade.

No dia 3 de janeiro de 1987, com o solo retirado das subparcelas através de trado manual, na profundidade de zero a $0,05 \mathrm{~m}$, realizou-se um bioensaio em casa de vegetação, utilizando-se milho (Zea mays L.) e alface (Lactuca sativa L.) como plantas-testes.

Um segundo experimento foi realizado com o herbicida clomazone (Gamit, $500 \mathrm{~g} / 1$ ), cuja solubilidade em água a $20-27^{\circ} \mathrm{C}$ é de $1100 \mathrm{ppm}$ e a pressão de vapor a $25^{\circ} \mathrm{C}$ é de $1,44.10 \mathrm{~mm} \mathrm{Hg}$ (Almeida \& Rodrigues, 1988). 0 experimento foi instalado no Centro Experimental do IAPAR em
Londrina, PR, em local com as mesmas características do $1^{\circ}$ experimento.

O delineamento experimental adotado foi o de blocos ao acaso, com parcelas subdivididas e quatro repetições. Os tratamentos foram constituídos pelas seguintes quantidades de cobertura morta: $0,375,750,1500,3000$ e $6000 \mathrm{~kg} / \mathrm{ha}$ de matéria seca. Os subtratamentos foram constituídos pelas doses do herbicida clomazone, aplicado a 0, 0,5, 0,75 e 1,0 $\mathrm{kg} / \mathrm{ha}$, correspondendo respectivamente às doses zero, $50 \%$ $\mathrm{N}, 75 \% \mathrm{~N}$ e $100 \% \mathrm{~N}$ (onde $\mathrm{N}=$ dose normal). A metodologia adotada na distribuição da palha e as dimensões das parcelas e subparcelas foram idênticas àquelas do $1^{\circ}$ experimento.

A cultivar de soja utilizada foi a "Paraná", semeada mecanicamente com semeadeira de plantio direto "Lavrale", densidade de 35 sementes/metro linear, espaçamento de 0,5 $\mathrm{m}$, profundidade de $0,05 \mathrm{~m}$, aplicando-se no sulco de semeadura $300 \mathrm{~kg} / \mathrm{ha}$ de adubo fórmula 04-30-10. 0 herbicida clomazone foi aplicado em pré-emergência, imediatamente após a semeadura da soja, com o mesmo equipamento utilizado no $1^{\circ}$ experimento. As condições climáticas quando da aplicação do produto encontram-se na Tabela 2.

Foram realizadas avaliações visuais de cobertura do solo pelas plantas daninhas no subtratamento sem herbicida, e de fitotoxicidade à cultura e controle de plantas daninhas nos demais subtratamentos, considerando-se o mesmo critério utilizado no $1^{\circ}$ experimento. As principais espécies infestantes deste experimento foram capim-marmelada e picão-preto.

Este segundo experimento foi levado à produção, sendo os dados submetidos à análise da variância, utilizando-se o teste de Tukey ao nível de 5\% de probabilidade.

No dia 11 de dezembro de 1987, com o solo retirado das subparcelas através de trado manual, na profundidade de zero a $0,05 \mathrm{~m}$, realizou-se um bioensaio em casa-de-vegetação, utilizando-se alface, milho e trigo como plantas testes. Os dados do bioensaio também foram submetidos à análise da variância, utilizando-se o teste de Tukey ao nível de 5\% de probabilidade.

TABELA 1. Condiçổes climáticas quando da aplicação do imazaquin ( $1^{9}$ experimento).

\begin{tabular}{|c|c|c|c|c|c|c|c|c|c|}
\hline \multirow{2}{*}{$\begin{array}{c}\text { Data de } \\
\text { aplicação }\end{array}$} & \multicolumn{3}{|c|}{ Temperatura $\left({ }^{\circ} \mathrm{C}\right)$} & \multirow{2}{*}{$\begin{array}{l}\text { U. R. ar } \\
(\%)\end{array}$} & \multicolumn{3}{|c|}{ Chuva $(\mathrm{mm})^{1}$} & \multirow{2}{*}{$\begin{array}{c}\text { Estado do } \\
\text { tempo }\end{array}$} & \multirow{2}{*}{ Vento } \\
\hline & Mín. & Méd. & Máx. & & -7 dias & $\mathbf{0}$ & +7 dias & & \\
\hline $02 / 10 / 86$ & 13,8 & 22,0 & 30,4 & 51,6 & 17,6 & 0 & 0 & claro & E \\
\hline
\end{tabular}

${ }^{1}$ A primeira chuva após a aplicação ocorreu dia 10/10/86; no dia 11/10/86 foram aplicados 15,0 mm de água por aspersảo.

TABELA 2. Condiçổes climáticas quando da aplicação do clomazone ( $2^{\circ}$ experimento).

\begin{tabular}{|c|c|c|c|c|c|c|c|c|c|}
\hline \multirow{2}{*}{$\begin{array}{c}\text { Data de } \\
\text { aplicaçấo }\end{array}$} & \multicolumn{3}{|c|}{ Temperatura $\left({ }^{\circ} \mathrm{C}\right)$} & \multirow{2}{*}{$\underset{(\%)}{\text { U. R. ar }}$} & \multicolumn{3}{|c|}{ Chuva $(\mathrm{mm})^{1}$} & \multirow{2}{*}{$\begin{array}{c}\text { Estado do } \\
\text { tempo }\end{array}$} & \multirow{2}{*}{ Vento } \\
\hline & Mín. & Méd. & Máx. & & -7 dias & $\mathbf{0}$ & +7 dias & & \\
\hline $27 / 11 / 87$ & 17,0 & 24,0 & 31,4 & 51,1 & 27,0 & 0 & 42,1 & nublado & W \\
\hline
\end{tabular}

${ }^{1}$ Foram aplicados $22 \mathrm{~mm}$ de água por aspersão imediatamente após a aplicaçăo do clomazone, ao final da tarde. Este valor não está computado nos $42,1 \mathrm{~mm}$ até sete dias depois. 


\section{RESULTADOS E DISCUSSÃO}

\section{$1^{\circ}$ experimento}

Verificou-se que o imazaquin não provocou fitotoxicidade à soja. Quanto ao controle do picão-preto (Tabela 3), aos 36 dias após a aplicação, observou-se que, em todos os tratamentos, independentemente da dose do imazaquin, o controle foi satisfatório (acima do nível 70). Aos 64 dias, no entanto, já se podia observar um controle insuficiente na dose menor $(0,075 \mathrm{~kg} / \mathrm{ha}$ i.a.), pois nova infestação estava ocorrendo. Notou-se também, a essa altura, que no tratamento com quantidade "zero" de cobertura morta, mesmo à dose maior ( $0,15 \mathrm{~kg} / \mathrm{ha}$ i.a.), o controle foi insuficiente, o que não ocorreu nos outros tratamentos com essa dose.

A Tabela 1 mostra que não ocorreram chuvas nem se fez irrigação até 7 dias após a aplicação do imazaquin. No entanto, a precipitação ocorrida ao $8^{\circ}$ dia $(9,7 \mathrm{~mm})$ e a irrigação efetuada ao $9^{\circ}$ dia $(15,0 \mathrm{~mm})$, além das irrigações subseqüentes, foram suficientes para arrastar o produto da palha para o solo. Este fato pode justificar o ocorrido no controle efetuado pelo produto nas três espécies citadas. Portanto, pelos dados apresentados, presume-se que a quantidade de palha não exerceu influência na atuação do imazaquin, fato também observado com atrazine por Erbach \& Lovely (1975) e com metolachlor, por Strek \& Weber (1982).

A Tabela 4 mostra os valores da produção da soja nesse experimento. Observa-se que houve aumento da produção, com o aumento das doses do tratamento. No entanto, não houve diferenças significativas de produção dentro de cada tratamento, quand o se comparam as doses 0,075, 0,1125 e $0,15 \mathrm{~kg} / \mathrm{ha}$, sem diferença estatística entre si. Isso demonstra que, nas condições em que o experimento foi conduzido, poder-se-ia utilizar doses menores do produto, sem reflexo na produção.

No bioensaio realizado em casa de vegetação, onde foram utilizados milho e alface como plantas-testes, observou-se aos 10 dias após a instalação do mesmo que o produto não provocou fitotoxicidade no milho (Tabela 5). No entanto, nítidos sintomas de encarquilhamento e necrose das folhas foram observados no alface, independentemente do tratamento de onde o solo foi retirado. Isso demonstra que o produto manteve ainda sua residualidade nos primeiros 0,05 $\mathrm{m}$ do solo a ponto de afetar uma cultura sensível como o alface, tendo sido passados, a essa altura, 93 dias entre a aplicação no campo e a instalação do bioensaio. Estes dados também confirmam a hipótese de que o imazaquin não teria ficado retido de forma significativa na cobertura morta.

TABELA 3. Porcentagem de controle de Bidens pilosa com diferentes doses de imazaquin, em diferentes quantidades de cobertura morta.

\begin{tabular}{|c|c|c|c|c|c|c|c|c|}
\hline \multirow{3}{*}{$\begin{array}{c}\text { Cobertura morta } \\
(\mathrm{kg} / \mathrm{ha})\end{array}$} & \multicolumn{4}{|c|}{$36 \mathrm{DDA}^{1}$} & \multicolumn{4}{|c|}{64 DDA } \\
\hline & \multicolumn{8}{|c|}{ Dose (kg/ha) } \\
\hline & $\mathbf{0}$ & $\mathbf{0 , 0 7 5 0}$ & 0,1125 & 0,1500 & $\mathbf{0}$ & 0,0750 & 0,1125 & 0,1500 \\
\hline \multirow{3}{*}{0} & & b & a & a & & a & a & a \\
\hline & 0 & $77 \mathrm{~b}$ & 89 a & $91 \mathrm{~b}$ & 0 & $50 \mathrm{c}$ & $58 \mathrm{c}$ & $61 \mathrm{~b}$ \\
\hline & & b & b & a & & b & b & a \\
\hline \multirow[t]{2}{*}{ hastes } & 0 & $87 \mathrm{ab}$ & 90 a & $98 \mathrm{ab}$ & 0 & 73 a & $78 \mathrm{~b}$ & 98 a \\
\hline & & b & a & a & & b & a & a \\
\hline \multirow[t]{2}{*}{750} & 0 & $83 a b$ & 97 a & $98 \mathrm{ab}$ & 0 & $63 a b c$ & $88 \mathrm{a}$ & 94 a \\
\hline & & b & $a b$ & a & & $\mathrm{c}$ & b & a \\
\hline \multirow[t]{2}{*}{1500} & 0 & $82 a b$ & 89 a & $97 a b$ & 0 & $51 \mathrm{c}$ & $65 \mathrm{c}$ & 95 a \\
\hline & & b & a & a & & c & b & a \\
\hline \multirow[t]{2}{*}{3000} & 0 & $77 \mathrm{~b}$ & 94 a & $97 a b$ & 0 & $56 \mathrm{bc}$ & $87 a b$ & 94 a \\
\hline & & b & ab & a & & b & b & a \\
\hline 6000 & 0 & 92 a & 96 a & 99 a & 0 & $68 \mathrm{ab}$ & $78 \mathrm{ab}$ & 95 a \\
\hline
\end{tabular}

Médias seguidas da mesma letra náo điferem entre si pelo teste de Tukey ao nível de $5 \%$ de probabilidade, sendo que letras sobre os números referem-se a efeitos de subtratamentos (doses) dentro de cada tratamento (quantidade de cobertura morta) ou comparaçáo na horizontal, e letras ao lado dos números referem-se a efeitos de tratamentos dentro de cada subtratamento, ou comparaçăo na vertical.

1 Dias depois da aplicaçăo. 
TABELA 4. Produção de soja $(\mathrm{kg} / \mathrm{ha})$ do ensaio com diferentes doses de imazaquin, em diferentes quantidades de cobertura morta.

\begin{tabular}{r|c|c|c|c}
\hline \multirow{2}{*}{$\begin{array}{c}\text { Cobertura } \\
\text { morta } \\
(\mathbf{k g} / \mathbf{h a})\end{array}$} & \multicolumn{4}{|c}{ Dose (kg/ha) } \\
\cline { 2 - 5 } & $\mathbf{0}$ & $\mathbf{0 , 0 7 5 0}$ & $\mathbf{0 , 1 1 2 5}$ & $\mathbf{0 , 1 5 0 0}$ \\
\hline & $\mathrm{b}$ & $\mathrm{ab}$ & $\mathrm{a}$ & a \\
0 & $693 \mathrm{a}$ & 1117 a & $1272 \mathrm{~b}$ & 1466 a \\
& $\mathrm{b}$ & ab & ab & ab \\
hastes & 834 a & 1180 a & $1298 \mathrm{~b}$ & 1657 a \\
& $\mathrm{b}$ & ab & a & a \\
750 & 770 a & 1163 a & 1528 ab & 1575 a \\
& b & a & a & a \\
1500 & 643 a & 1285 a & 1471 ab & 1529 a \\
& b & ab & a & a \\
3000 & 870 a & 1299 a & 1578 ab & 1554 a \\
& b & a & a & a \\
6000 & 890 a & 1556 a & 1806 a & 1778 a \\
\hline
\end{tabular}

Médias seguidas da mesma letra nāo diferem entre si pelo teste de Tukey ao nível de $5 \%$ de probabilidade, sendo que letras sobre os números referem-se a efeitos de subtratamentos (doses) dentro de cada tratamento (quantidade de cobertura morta) ou comparaçáo na horizontal, e letras ao lado dos números referem-se a efeitos de tratamentos dentro de cada subtratamento, ou comparaçăo na vertical.

\section{$2^{2}$ experimento}

Analisando-se a Tabela 6, verifica-se que houve redução do controle do picão-preto com o aumento da quantidade de cobertura morta, independentemente da dose de clomazone utilizada. Com isso, fica evidente que apenas uma parte do produto atingiu o solo. Deve-se levar em consideração que foram aplicados $22 \mathrm{~mm}$ de água por aspersão em todo o experimento, imediatamente após a aplicação do herbicida e que, até aos 25 dias depois da aplicação (época da avaliação visual) choveu $154,2 \mathrm{~mm}$, além da irrigação por aspersão efetuada. Presume-se que esta quantidade de água seria suficiente para arrastar o produto para o solo, o que certamente não aconteceu. Estes dados, estão de acordo com os obtidos por Mills et al. (1989) com o próprio clomazone, por Banks \& Robinson (1982) com metribuzin e por Banks \& Robinson (1984) com oryzalin.

Pela Tabela 7 observa-se que houve aumento na produção da soja com o aumento da dose do produto em todas as quantidades de cobertura morta testadas. No entanto, não houve diferença significativa entre essas quantidades, dentro de cada dose de clomazone estudada.

Para confirmar a hipótese de que apenas parte do produto atingiu o solo, basta observar os dados obtidos no bioensaio (Tabelas 8 e 9). Em todos os casos houve redução do sintoma de fitotoxicidade nas plantas-testes utilizadas
TABELA 5. Porcentagem de fitotoxicidade no milho e no alface aos $\mathbf{1 0}$ dias após a semeadura do bioensaio ${ }^{1}$ com imazaquin, em solo coletado de zero a $0,05 \mathrm{~m}$ de profundidade.

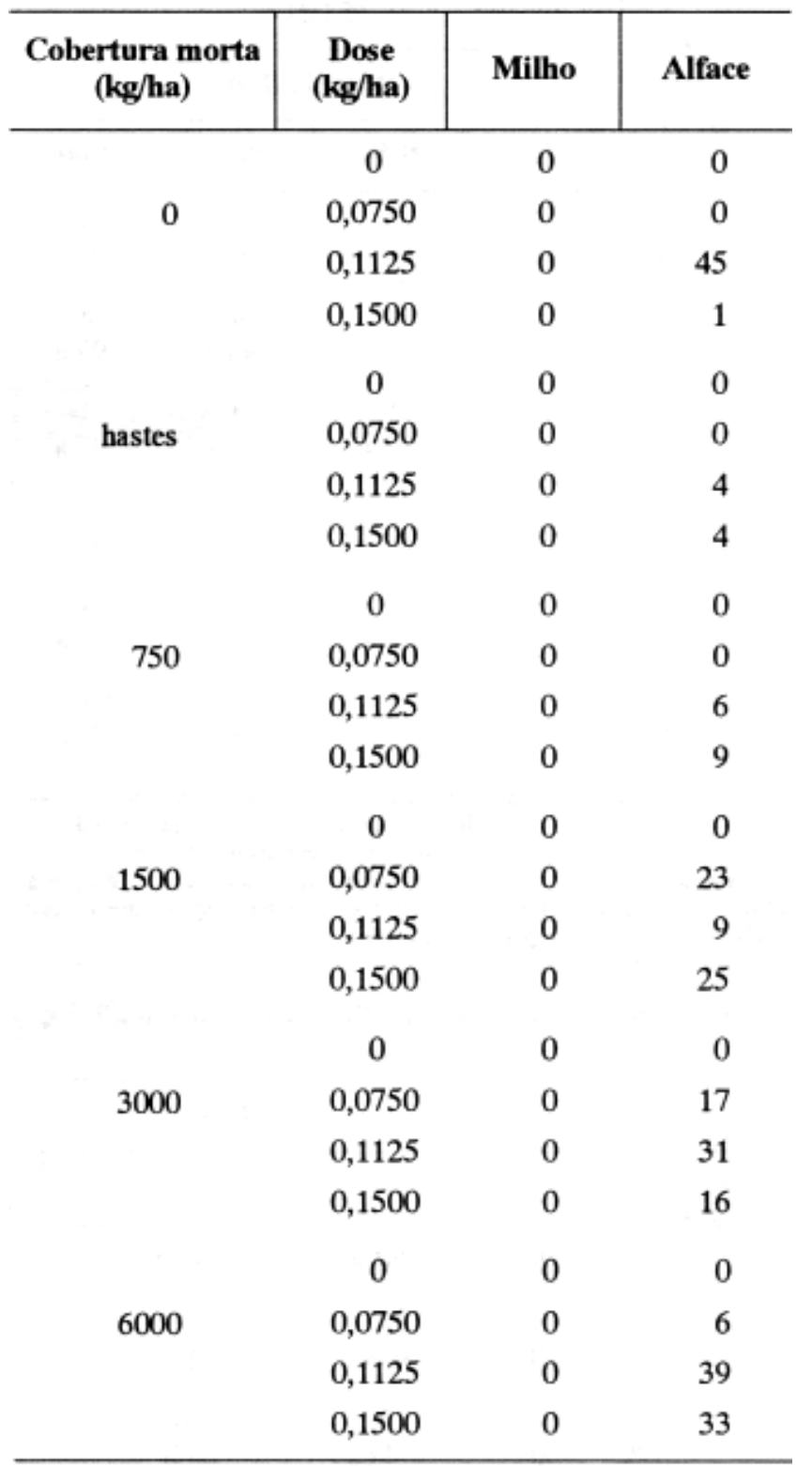

${ }^{1}$ Bioensaio instalado 93 dias após a aplicação do imazaquin no campo.

(alface, milho e trigo), com o aumento da quantidade de cobertura morta, sintoma este evidenciado por "branqueamento" característico do clomazone. O sintoma ficava mais evidente, à medida que se aumentava a dose do produto, independentemente da quantidade de palha utilizada.

\section{Considerações finais}

Dos dois herbicidas utilizados no presente trabalho, apenas o clomazone mostrou evidencias de ter sido interceptado pela cobertura morta, com isto reduzindo a quantidade de produto que teria atingido o solo. Este produto é mais solúvel que o imazaquin, tendo 1100 ppm contra 60 ppm do 
B.N. Rodrigues

TABELA 6. Porcentagem do controle de Bidens pilosa com diferentes doses de clomazone, em diferentes quantidades de cobertura morta.

\begin{tabular}{|c|c|c|c|c|}
\hline \multirow{3}{*}{$\begin{array}{c}\text { Cobertura } \\
\text { morta } \\
\text { (kg/ha) }\end{array}$} & \multicolumn{4}{|c|}{25 DDA $^{1}$} \\
\hline & \multicolumn{4}{|c|}{ Dose (kg/ha) } \\
\hline & 0 & $\mathbf{0 , 5 0}$ & 0,75 & 1,00 \\
\hline & & a & a & a \\
\hline \multirow[t]{2}{*}{0} & 0 & $93 \mathrm{ab}$ & 97 a & 97 a \\
\hline & & a & a & a \\
\hline \multirow[t]{2}{*}{375} & 0 & 95 a & 96 a & 97 a \\
\hline & & b & a & a \\
\hline \multirow[t]{2}{*}{750} & 0 & $83 \mathrm{c}$ & 95 a & 97 a \\
\hline & & b & a & a \\
\hline \multirow[t]{2}{*}{1500} & 0 & 88 bc & 96 a & 98 a \\
\hline & & b & b & a \\
\hline \multirow[t]{2}{*}{3000} & 0 & $88 \mathrm{bc}$ & $84 b$ & 97 a \\
\hline & & a & a & a \\
\hline 6000 & 0 & $64 \mathrm{~d}$ & $68 \mathrm{c}$ & $70 \mathrm{~b}$ \\
\hline
\end{tabular}

Médias seguidas da mesma letra nâo diferem entre si pelo teste de Tukey ao nível de $5 \%$ de probabilidade, sendo que letras sobre os números referem-se a efeitos de subtratamentos (doses) dentro de cada tratamento (quantidade de cobertura morta) ou comparaçäo na horizontal, e letras ao lado dos números referem-se a efeitos de tratamentos dentro de cada subtratamento, ou comparação na vertical.

1 Dias depois da aplicaçắo.
TABELA 7. Produçäo da soja no experimento com diferentes doses de clomazone em diferentes quantidades de cobertura morta.

\begin{tabular}{|c|c|c|c|c|}
\hline \multirow{2}{*}{$\begin{array}{c}\text { Cobertura } \\
\text { morta } \\
(\mathrm{kg} / \mathrm{ha})\end{array}$} & \multicolumn{4}{|c|}{ Dose (kg/ha) } \\
\hline & $\mathbf{0}$ & 0,50 & 0,75 & 1,00 \\
\hline \multirow{3}{*}{0} & b & a & a & a \\
\hline & $342 \mathrm{ab}$ & $1163 \mathrm{ab}$ & 1344 a & $1420 \mathrm{a}$ \\
\hline & b & a & a & a \\
\hline \multirow[t]{2}{*}{375} & $239 \mathrm{~b}$ & $1038 \mathrm{ab}$ & 1315 a & $1225 \mathrm{a}$ \\
\hline & b & b & a & a \\
\hline \multirow[t]{2}{*}{750} & $265 \mathrm{~b}$ & $841 \mathrm{~b}$ & $1540 \mathrm{a}$ & $1675 \mathrm{a}$ \\
\hline & b & a & a & a \\
\hline \multirow[t]{2}{*}{1500} & $231 \mathrm{~b}$ & $1210 \mathrm{ab}$ & 1721 a & 1657 a \\
\hline & b & a & a & a \\
\hline \multirow[t]{2}{*}{3000} & 855 a & 1511 a & 1513 a & $1640 \mathrm{a}$ \\
\hline & b & $a b$ & a & a \\
\hline 6000 & $697 a b$ & $1152 \mathrm{ab}$ & $1553 \mathrm{a}$ & $1373 \mathrm{a}$ \\
\hline
\end{tabular}

Médias seguidas da mesma letra nåo diferem entre si pelo teste de Tukey ao nível de $5 \%$ de probabilidade, sendo que letras sobre os números referem-se a efeitos de subtratamentos (doses) dentro de cada tratamento (quantidade de cobertura morta) ou comparaçăo na horizontal, e letras ao lado dos números referem-se a efeitos de tratamentos dentro de cada subtratamento, ou comparaçäo na vertical.

TABELA 8. Porcentagem de fitotoxicidade em alface, em bioensaio com clomazone ${ }^{1}$, com solo retirado de zero a 0,05 m de profundidade.

\begin{tabular}{|c|c|c|c|c|c|c|c|c|}
\hline \multirow{3}{*}{$\begin{array}{c}\text { Cobertura } \\
\text { morta } \\
(\mathbf{k g} / \mathbf{h a})\end{array}$} & \multicolumn{4}{|c|}{$7 \mathrm{DDS}^{2}$} & \multicolumn{4}{|c|}{17 DDS } \\
\hline & \multicolumn{8}{|c|}{ Dose (kg/ha) } \\
\hline & $\mathbf{0}$ & 0,50 & 0,75 & 1,00 & $\mathbf{0}$ & 0,50 & 0,75 & 1,00 \\
\hline 0 & 0 & $\begin{array}{c}a \\
38 \text { a }\end{array}$ & $\begin{array}{c}\text { a } \\
54 \text { a }\end{array}$ & $\begin{array}{c}\mathrm{a} \\
39 \mathrm{~b}\end{array}$ & 0 & $\begin{array}{c}a \\
27 a\end{array}$ & $\begin{array}{c}\text { a } \\
36 \text { a }\end{array}$ & $\begin{array}{c}\mathrm{a} \\
35 \mathrm{~b}\end{array}$ \\
\hline 375 & 0 & $\begin{array}{c}\mathrm{c} \\
4 \mathrm{~cd}\end{array}$ & $23 \mathrm{~b}$ & $\begin{array}{r}a \\
68 \mathrm{a}\end{array}$ & 0 & $\begin{array}{c}c \\
4 \mathrm{c}\end{array}$ & $\begin{array}{c}b \\
17 b c\end{array}$ & $\begin{array}{c}a \\
68 \mathrm{a}\end{array}$ \\
\hline 750 & 0 & $\begin{array}{c}a b \\
26 \mathrm{ab}\end{array}$ & $\begin{array}{c}b \\
17 b\end{array}$ & $\begin{array}{c}\mathrm{a} \\
38 \mathrm{~b}\end{array}$ & 0 & $\begin{array}{c}b \\
12 b\end{array}$ & $\begin{array}{c}b \\
12 \mathrm{~cd}\end{array}$ & $\begin{array}{c}a \\
32 b\end{array}$ \\
\hline 1500 & 0 & $\begin{array}{c}c \\
2 d\end{array}$ & $\begin{array}{c}\mathrm{b} \\
19 \mathrm{~b}\end{array}$ & $\begin{array}{c}a \\
49 \\
a b\end{array}$ & 0 & $\begin{array}{c}b \\
2 c\end{array}$ & $\begin{array}{c}b \\
7 d\end{array}$ & $\begin{array}{c}a \\
26 b\end{array}$ \\
\hline 3000 & 0 & $\begin{array}{c}\mathrm{c} \\
11 \mathrm{bcd}\end{array}$ & $\begin{array}{c}\mathrm{b} \\
32 \mathrm{~b}\end{array}$ & $\begin{array}{c}\mathrm{a} \\
61 \mathrm{a}\end{array}$ & 0 & $\begin{array}{c}\mathrm{b} \\
12 \mathrm{~b}\end{array}$ & $\begin{array}{c}a \\
27 \mathrm{ab}\end{array}$ & $\begin{array}{c}\mathrm{a} \\
32 \mathrm{~b}\end{array}$ \\
\hline 6000 & 0 & $\begin{array}{c}\mathbf{b} \\
12 \mathrm{bc}\end{array}$ & $\begin{array}{r}a b \\
18 \mathrm{~b}\end{array}$ & $32 \mathrm{~b}$ & 0 & $\begin{array}{c}\mathrm{a} \\
1 \mathrm{c}\end{array}$ & $\underset{5 d}{a}$ & $\begin{array}{c}a \\
5 \mathrm{c}\end{array}$ \\
\hline
\end{tabular}

Médias seguidas da mesma letra näo diferem entre si pelo teste de Tukey ao nível de $5 \%$ de probabilidade, sendo que letras sobre os números referem-se a efeitos de subtratamentos (doses) dentro de cada tratamento (quantidade de cobertura morta) ou comparaçăo na horizontal, e letras ao lado dos números referem-se a efeitos de tratamentos dentro de cada subtratamento, ou comparaçăo na vertical.

${ }_{1}^{1}$ Bioensaio instalado 14 dias após a aplicação do clomazone no campo.

2 Dias depois da semeadura. 
TABELA 9. Porcentagem de fitotoxicidade em milho, em bioensaio com clomazone ${ }^{1}$, com solo retirado de zero a 0,05 m de profundidade.

\begin{tabular}{|c|c|c|c|c|c|c|c|c|}
\hline \multirow{3}{*}{$\begin{array}{c}\text { Cobertura } \\
\text { morta } \\
(\mathrm{kg} / \mathrm{ha})\end{array}$} & \multicolumn{4}{|c|}{7 DDS $^{2}$} & \multicolumn{4}{|c|}{17 DDS } \\
\hline & \multicolumn{8}{|c|}{ Dose (kg/ha) } \\
\hline & $\mathbf{0}$ & $\mathbf{0 , 5 0}$ & 0,75 & 1,00 & $\mathbf{0}$ & 0,50 & 0,75 & 1,00 \\
\hline \multirow{3}{*}{0} & & a & a & a & & a & $a b$ & b \\
\hline & 0 & $46 a$ & $46 a$ & $49 \mathrm{bc}$ & 0 & 45 a & 33 a & $25 \mathrm{~b}$ \\
\hline & & c & b & a & & c & b & $\mathbf{a}$ \\
\hline \multirow[t]{2}{*}{375} & 0 & $4 \mathrm{c}$ & $37 \mathrm{ab}$ & $58 \mathrm{ab}$ & 0 & $4 \mathrm{bc}$ & 32 a & 54 a \\
\hline & & a & a & a & & b & $a b$ & a \\
\hline \multirow[t]{2}{*}{750} & 0 & $24 \mathrm{~b}$ & $22 \mathrm{bc}$ & $32 \mathrm{~cd}$ & 0 & $9 \mathrm{~b}$ & $15 \mathrm{~b}$ & $25 \mathrm{~b}$ \\
\hline & & c & b & a & & b & $a b$ & a \\
\hline \multirow[t]{2}{*}{1500} & 0 & $5 \mathrm{c}$ & $22 \mathrm{bc}$ & 71 a & 0 & $1 \mathrm{c}$ & $7 \mathrm{bc}$ & $17 \mathrm{~b}$ \\
\hline & & b & b & a & & b & b & $\mathrm{a}$ \\
\hline \multirow[t]{2}{*}{3000} & 0 & $10 \mathrm{c}$ & $12 \mathrm{~cd}$ & $30 \mathrm{~d}$ & 0 & $7 \mathrm{bc}$ & $11 \mathrm{bc}$ & $24 \mathrm{~b}$ \\
\hline & & a & a & a & & a & a & a \\
\hline 6000 & 0 & $6 \mathrm{c}$ & $7 \mathrm{~d}$ & $11 \mathrm{e}$ & 0 & $2 c$ & $4 \mathrm{c}$ & $4 \mathrm{c}$ \\
\hline
\end{tabular}

Médias seguidas da mesma letra nāo diferem entre si pelo teste de Tukey ao nível de $5 \%$ de probabilidade, sendo que letras sobre os números referem-se a efeitos de subtratamentos (doses) dentro de cada tratamento (quantidade de cobertura morta) ou comparaçăo na horizontal, e letras ao lado dos números referem-se a efeitos de tratamentos dentro de cada subtratamento, ou comparaçăo na vertical.

1 Bioensaio instalado 14 dias após a aplicaçăo do clomazone no campo.

2 Dias depois da semeadura.

imazaquin. Da mesma forma, o clomazone é mais volátil, com valores da ordem de $10^{4} \mathrm{mmHg}$, contra $10^{-8} \mathrm{mmHg}$ do imazaquin (Almeida \& Rodrigues, 1988).

Com esses dados, poder-se-ia concluir que quanto maior a solubilidade em água e maior a volatilidade de um produto, tanto menor é a capacidade de um herbicida préemergente, residual, em atingir o solo no sistema de plantio direto, hipóteses também sugeridas por Strek \& Weber (1982) e por Mills et al. (1989), respectivamente. Estes resultados são, em alguns casos, condizentes com os obtidos por alguns autores, como por Erbach \& Lovely (1975) com atrazine em cobertura morta de milho, Strek \& Weber (1982) com metolachlor e Mills et al. (1989) com clomazone, ambos em cobertura morta de trigo. Por outro lado, no entanto, são conflitantes com os obtidos por Pastana (1972) com atrazine em cobertura morta de aveia e Crutchfield et al. (1985) com metolachlor em cobertura morta de trigo.

Outros pesquisadores, utilizando produtos diferentes, obtiveram resultados ora condizentes, ora conflitantes com es sa hipótese. Banks \& Robins on (1982), utilizando metribuzin (1200 ppm de solubilidade e $10-^{5} \mathrm{mmHg}$ de pressão de vapor), e Banks \& Robinson (1984), utilizando oryzalin $\left(2,5 \mathrm{ppm}\right.$ e $10-{ }^{7} \mathrm{mmHg}$, respectivamente), verific aram que a cobertura morta de trigo interceptou ambos os produtos, reduzindo a quantidade que efetivamente atingiu o solo.

Diante desses dados, a hipótese mais provável é que a capacidade de um herbicida residual em atingir o solo, no sistema de plantio direto, não depende apenas da solubilidade em água e da volatilidade do produto. Outros fatores também poderiam influir no comportamento desses herbicidas no solo, tais como quantidade e origem da cobertura morta, quantidade e época da primeira irrig ação ocorrida após a aplicação do produto, assim como as irrigações subseqüentes, condições climáticas prevalescentes durante e após a aplicação, entre outros. Além disso, algumas características relacionadas ao próprio solo como textura, por exemplo, poderiam também influir na maior ou menor adsorção do produto aos colóides (Hassall, 1982). Esse fato poderia, consequentemente, influir na lixiviação do produto para as camadas mais profundas do solo com a água de irrigação, reduzindo, neste caso, o teor do produto na camada superficial do solo que é utilizada, na maioria dos trabalhos, em análises cromatográficas de resíduos ou em bioensaios com plantas-testes.

Outro fato que também deve merecer atenção é a ação conjunta dos herbicidas residuais com a ação física (apenas como cobertura) ou biológica (por alelopatia) exercida pela cobertura morta no controle das plantas daninhas. Nesse caso, as pesquisas deveriam ser direcionadas no sentido de se estudar esses fatores tanto separadamente como de forma integrada, devido a grande variação de características que existe, tanto dos herbicidas quanto das coberturas mortas.

Diante do exposto, sugere-se que os estudos sobre o comportamento dos herbicidas residuais no sistema de plantio direto devam ser intensificados, principalmente nas condições de clima tropical, como é o caso do Brasil. Para isso, uma importante ferramenta já utilizada por alguns autores é a análise cromatográfica de resíduos dos herbicidas na palha e 
no solo, que, somada às avaliações de campo e aos bioensaios, completa uma metodologia que pode nos fornecer importantes subsídios, visando às recomendações de uso de herbicidas, tanto no sistema de plantio direto como no convencional.

Os resultados obtidos permitem concluir que:

1. A capacidade de um herbicida pré-emergente, residual, em atingir o solo no sistema de plantio direto varia conforme o produto.

2. Essa capacidade é dependente de fatores inerentes não só ao próprio produto, como também à cobertura morta e às condições ambientais prevalescentes durante e após a aplicação de cada um deles.

3. Dos herbicidas estudados, o clomazone mostrou evidências de ter sido interceptado pela cobertura morta; o mesmo não ocorreu em relação ao imazaquin.

\section{LITERATURA CITADA}

ALMEID A, F.S. A alelopatia e as plantas. Londrina, IAPAR, 1988. 60p. (IAPAR. Circular, 53).

ALMEIDA, F.S. Controle de ervas. In: Fundação Instituto Agronômico do Paraná, Londrina, PR. Plantio direto no Estado do Paraná. Londrina, 1981. p. 101-44. (Circular IAPAR, 23).

ALMEIDA, F.S. Herbicidas residuais em diferentes sistemas de preparo do solo. Pesquisa Agropecuária Brasileira, Brasília, 27(4): 596-601, 1992.

ALMEIDA, F.S. \& RODRIGUES, B.N. Guia de Herbicidas. $2^{\mathrm{a}}$ ed. Londrina, Ed. dos autores, 1988. 603 p.

BANKS, P.A. \& ROBINSON, E.L. Soil reception and activity of acetochlor, alachlor and metolachlor as affected by wheat (Triticum aestivum) straw and irrigation. Weed Science, Champaign, 34: 607-611, 1986.
BANKS, P.A. \& ROBINSON, E.L. The influence of straw mulch on the soil reception and persistence of metribuzin. Weed Science, Champaign, 30: 164-168, 1982.

BANKS, P.A. \& ROBINSON, E.L. The fate of oryzalin applied to straw-mulched and nonmulched soils. Weed Science, Champaign, 32: 269-272, 1984.

BAUMAN, T.T. Amount and persistence of atrazine in soil with three tillage systems. Dissertation Abstracts International, v .37, n .10, p .4794-4795, 1977.

CRUTCHFIELD, D.A.; WICKS, G.A.; BURNSIDE, O.C. Effect of winter wheat (Triticum aestivum) straw mulch level on weed control. Weed Science, Champaign, 34: 110-114, 1985.

ERBACH, D.C.; LOVELY, W.G. Effect of plant residue on herbicide performance in no-tillage corn. Weed Science, Champaign, 23: 512-515, 1975.

HASSALL, K.A. The chemistry of pesticides. Basel, Verlag Chemie, 1982. 372p.

LOWDER, S.W. \& WEBER, J.B. Atrazine retention by crop residues in reduced-tillage systems. Proceedings Southern Weed Science Society, v.32, p.303-307, 1979.

MILLS, J.A.; WITT, W.W.; BARRETT, J. Effects of tillage on the efficacy and persistence of clomazone in soybean (Glycine max). Weed Science, Champaign, 37: 217-222, 1989.

PASTANA, F.I. Efeito da retenção de um herbicida pela cobertura morta do solo, no controle das ervas daninhas e na produção do milho com cultivo mínimo. Bragantia, Campinas, 31: 259-274, 1972.

STREK, H.J. \& WEBER, J.B. Adsorption, mobility and activity comparisons between alachlor (Lasso) and metolachlor (Dual). Proceedings Southern Weed Science Society, v.35, p.332-8, 1982.

THELAN, K.D.; KELLS, J.J.; PENNER, D. Rotational crop response and volatilization with FMC-57020. Proc. North Cent. Weed Control Conf. v.41, p.48. 1986. 